\title{
How suitable is the macro-micro parametric distinction in acquisition?
}

\author{
Laura Domínguez \\ University of Southampton
}

It is easy to agree with Tsimpli that debates on language acquisition need to be informed by developments in linguistic theory (Minimalism in this case). I also fully agree that revisiting standing issues in bilingual acquisition, such as input and age of onset, following a formal, linguistic perspective is necessary. However, in this commentary Tsimpli has not helped her case by linking early acquisition with macroparameters (perhaps the most contested concept in current Minimalist theory), nor by maintaining the view that the distinction between narrow-syntactic and interface-based phenomena can be used to reliably predict problems in acquisition.

Tsimpli proposes that the timing of emergence of structures in monolingual grammars can be used to predict what structures will be acquired early (and late) in bilingual acquisition. She distinguishes between early structures which are 'core', parametric and narrow syntactic, whereas late phenomena are syntax-external and/or language external and their acquisition relies on sufficient exposure to input. Her main argument is that bilinguals set the narrow syntactic options early whereas late bilinguals set the microparametric/language external options late. Crucially, none have problems with macroparameters which she characterises as being "an overarching property of a language, the backbone defining the type of language the learner is exposed to." (p. 3, $2^{\text {nd }}$ paragraph) Tsimpli explains that each macroparameter is associated with a number of microparameters. She characterises macroparameters as being language internal (syntax and semantics), whereas some aspects or microparameters are language external (for Tsimpli this is pragmatics, lexical knowledge, semantics and working memory).

The article discusses the acquisition of two binary-valued bona fide macroparameters, the headcomplement parameter and the null subject parameter (NSP) (Baker 2008). Grammatical gender, which is syntactically represented by a formal feature, is also discussed. Macro-parameters flourished in the pre-Minimalist 'Principles and Parameters $(\mathrm{P} \& \mathrm{P})$ ' era at a time when UG (the genetic endowment all children are born with) was regarded as having a highly articulated structure. Parameters were desirable because they could explain successful and fast acquisition under poor input conditions. One particularly attractive aspect of microparameters was the fact that once a parameter was set to the correct value a number of related syntactic properties would be automatically be acquired as well (the 'switchboard metaphor' in Chomsky 1986). Minimal input and a substantially rich UG could thus substantially reduce the burden of the task faced by children. It was also thought that macroparameters had to be acquired early as a result of the relevant role of UG in explaining variation and acquisition and the minimal role of input in their acquisition (a notion well captured in Wexler's (1998) 'Very Early Parameter Setting').

\section{The status of macroparameters in Minimalism}

It is easy to see why Tsimpli has chosen macroparameters to explain variation. Once macroparameters are assumed, fast acquisition of core syntactic phenomena with minimal input follows. This can then explain why certain structures are acquired earlier than others. However, the status of macroparameters is currently under much debate in Minimalism as they are difficult to reconcile with 
the main premise of this programme: UG should be as small as possible (possibly including just the operation Merge and a set of universal features) due to evolutionary restrictions on the language faculty (Hauser et al. 2002; Berwick and Chomsky 2011).

The notion of parameter itself has suffered theoretical and empirical scrutiny over the years (see Culicover 1999; Boeckx 2010, 2011; Newmeyer 2004, 2005; Gallego 2011). Accumulating evidence has revealed that big macroparameter differences can also be captured by clustering of microparameters (see Newmeyer 2005; Boeckx 2011; Richards 2008). The exhaustive analysis of the main properties of the NSP by Camacho (2013) certainly supports this view. Haider (2012) also shows that OV/VO interacts closely with V2 in Germanic. More importantly, evidence from acquisition research has questioned the key role of (macro) parameters for a number of reasons. For instance, Yang (2002) argues that V2 in Dutch is acquired late (see also Haegeman 1995) and that Dutch children entertain various different grammatical options (including V1) before they converge on the target grammar. For Yang, timing in acquisition is a consequence of the interaction between UG and the linguistic patterns found in the input. Furthermore, it is now believed that a root infinitive stage is indeed present in the grammar of children acquiring a wide range of null subject languages such as Spanish (Grinstead 2004), Greek (Varlokosta,Vainikka \& Rohrbacher (1996) and Hyams (2005)), Korean (Kim and Phillips 1998), Italian (Salustri \& Hyams 2006), Chinese (Chien 2008) and Japanese (Murasugi \& Fuji 2011). English children who acquire a non-null subject language are known for dropping subjects at a higher rate than adults until the age of 3 and a half. Comprehension data discussed in Orfitelli \& Hyams (2012) shows that children assign a different interpretation to null subjects than adults during the null subject stage. It has been found that bilingual English-Spanish children overuse overt subjects in Spanish (Paradis \& Navarro 2003). Overall, these results seriously question the view that macroparameters, even those as fundamental as V2 and the NSP, are acquired fast and without problems. In principle late acquisition of a parameter is still compatible with a view of acquisition which is UG constrained (see Rizzi 2006).

Where should variation be located in a maximally-underspecified UG? Chomsky has proposed three factors in the design of the language faculty: I. genetic endowment, II. experience and III. principles not specific to the language faculty (e.g. interface conditions and principles of computational efficiency). Minimalism explores the interaction between Factor I) (and features made available by UG in particular) and Factor II) (see Roberts \& Roussou 2003; Holmberg \& Roberts 2009; Biberauer 2008). A number of possibilities for variation have been proposed, including variation in the formal features of lexical items as suggested by Borer (1984) and adopted by Chomsky (1995, 2000, 2001, 2007, 2008); the syntax-PF interface (i.e. externalisation) ${ }^{1}$, as well as proposals which see variation outside the grammar altogether and focus on Factor III effects (Richards 2008). In contrast, macroparameters assume that variation is in the core of the grammar (Factor I, Baker 2008). Tsimpli implies that macroparameters marry well with the 'Borer-Chomsky conjecture' but this is at least questionable, unlike microparameters which show variation at the level of the Lexicon (see Belletti \& Rizzi 1996; Biberauer et al. 2010; Gallego in press). Macroparameters seem better suited to account for big trends across E-languages (differences from the top down) than to capture the essence of variation in I-language in the Minimalist framework, which considers looking at variation from the bottom up (see Boeckx 2011).

\footnotetext{
${ }^{1}$ Externalisation is understood as transfer from the syntax to the morphophonological component (Gallego 2011:546). Variation is thus regarded as a spell-out/pronunciation issue.
} 
Furthermore, Tsimpli's proposal (focusing on timing alone) sweeps under the carpet any of the problems regarding the acquisition of V2 and the NSP mentioned earlier. Rizzi (2006) argues "The study of development reveals that early productions are not mere structural copies of adult utterances: there are certain systematic discrepancies which call for an explanation. One important task of developmental linguistics is to precisely describe these discrepancies, and the changes they undergo." This implies that focusing on whether children acquire something early (or they recognise a certain pattern in their language like Tsimpli argues) ${ }^{2}$ fails to engage with some of the fundamental issues which the field is addressing.

\section{What could be the cause of late parameter setting?}

Tsimpli argues that how late a structure emerges may depend on its interface status. However, a large body of research on the status of interfaces in language acquisition and native language attrition has shown that there is no clear evidence to support the view that the syntax-pragmatics interface is intrinsically problematic (see Domínguez 2013 for a review). Explaining problems in acquisition as the result of the syntax-semantics and syntax-pragmatics interface (whereas the syntax-phonology interface has a privileged status as noted by Tsimpli) is not fully justified on theoretical grounds either. The assumed architecture of the language faculty does not validate the view that the mapping from syntax to pragmatics and semantics should pose a problem in acquisition. A number of models, including the model proposed by Reinhart (2006), see aspects of context/pragmatics/discourse as being internal to the grammar. It is difficult to see how the architecture itself would be the cause of problems in child acquisition, although maturational constraints might restrict processing capabilities which would specifically target certain structures which violate constraints of narrow syntax in favour of interface interpretability (see Reinhart 2006; Domínguez 2013). The proposal that lateness in acquisition can be directly linked to maturational constraints (including processing limitation) has been recognised (see Rizzi 2006). Although this possibility is indeed mentioned by Tsimpli in her keynote article, the idea is never fully developed.

A similar argument applies to the syntax-semantics interface. In Minimalism, semantic representations are uniform and not subject to cross-linguistic variation. Computations of narrow syntax are optimal for interpretation at LF, whereas a locus of variation is the mapping from syntax to PF. Boeckx (2011) notes how in recent Minimalist proposals (see Chomsky 2008) the mapping from syntax to meaning is privileged over the mapping to sound and that a uniform narrow syntax is specifically designed "to meet the uniform demands at the meaning side in an optimal fashion. (Boeckx 2011:213)." We must assume that the advantaged status of the syntax-semantics interface is facilitated by the architecture of the grammar, and thus must be universally represented in all languages be accessible to children during acquisition.

\footnotetext{
${ }^{2}$ Note that characterising 'early' and 'late' is not without problems. For instance, Valian (1991) sets the standard of early acquisition at age 3 . In contrast, Yang $(2002,2011)$ claims that this should be considered late due to the amount of evidence available in the input. Tsimpli sets the standard for early acquisition before 2-3 years of age although Greek gender (which for her is acquired early) is acquired at 3 years and a half.
} 


\section{Where do we go from here?}

Although the postulation of macroparameters might not be the right alternative to a user-based approach, innate constraints are important in acquisition and Tsimpli is right to focus on this area. The alternative is also not necessarily to assume that input plays little role in early stages in acquisition, nor is this incompatible with the view that UG plays an important role. Emphasis on variation at the microparameter level can resolve this tension. Recently, it has been shown that probabilistic learning based on input frequency is compatible with the existence of UG (Yang's (2002) 'Variationist model') or cognitive biases along parametric lines (Culbertson, Smolensky \& Wilson 2013). In contrast to Tsimpli's proposal, the type of cues available in the input is crucial to understand the acquisition processes in these accounts (see Pearl \& Lidz 2013).

Tsimpli rightly argues that timing differences in acquisition can be (and should be) accounted for by Minimalist views on variation. Minimalism allows us to move away from a Factor I account (macroparameters) and to reassess the relevance of both Factor II (linguistic input) and Factor III (computation efficiency and maturation) in explaining variation and acquisition.

\section{References:}

Baker, M.C. (2008). The macroparameter in a microparametric world. In T. Biberauer (Ed.), The Limits of Syntactic Variation (pp. 351-373). Amsterdam: John Benjamins.

Berwick, R.C., \& Chomsky, N. (2011). The biolinguistic program: The current state of its evolution and development. In A. M. Di Sciullo \& C. Boeckx (Eds.), The biolinguistic enterprise: New perspectives on the evolution and nature of the human language faculty. Oxford: Oxford University Press.

Belletti, A. \& L. Rizzi. (1996). Parameters and Functional Heads. Oxford: Oxford University Press.

Biberauer, T. (Ed.) (2008). The Limits of Syntactic Variation. Amsterdam: John Benjamins.

Biberauer, T., Holmberg, A., Roberts, I., \& Sheehan, M. (Eds.) (2010). Parametric Variation: Null Subjects in Minimalist Theory. Cambridge: Cambridge University Press.

Boeckx, C. (2010). What Principles and Parameters Got Wrong. Ms., ICREA-UAB.

Boeckx, C. (2011). Approaching parameters from below. In A. M. Di Sciullo \& C. Boeckx (Eds.), The biolinguistic enterprise: New perspectives on the evolution and nature of the human language faculty. Oxford: Oxford University Press.

Borer, H. (1984). Parametric Syntax: Case Studies in Semitic and Romance Languages. Dordrecht: Foris.

Camacho, J. A. (2013). Null Subjects. Cambridge: Cambridge University Press.

Chien, M. (2008). Is there a Root Infinitive or Root Infinitive Analogue Stage in Early Mandarin? Ms. National Tsing Hua University, Taiwan. 
Chomsky, N. (1981). Lectures on Government and Binding. Dordrecht: Foris Publications.

Chomsky, N. (1986). Knowledge of Language. New York: Praeger.

Chomsky, N. (1995). The minimalist program. Cambridge, MA: MIT press.

Chomsky, N. (2000). Minimalist Inquiries: The Framework. In R. Martin et al. (Eds.), Step by Step. Essays on Minimalist Syntax in Honor of Howard Lasnik,(pp. 89-155). Cambridge, MA: MIT Press.

Chomsky, N. (2001). Derivation by Phase. In M. Kenstowicz (Ed.), Ken Hale: A Life in Language, (pp. 1-52). Cambridge, MA: MIT Press.

Chomsky, N. (2004). Beyond Explanatory Adequacy. In A. Belletti (Ed.), Structures and Beyond. The Cartography of Syntactic Structures (vol. 3), (pp. 104-131). Oxford, NY: Oxford University Press.

Chomsky, N. (2007). Approaching UG from below. In U. Sauerland \& H-M. Gärtner (Eds.), Interfaces + Recursion $=$ Language?, (pp. 1-30). Berlin: Mouton de Gruyter.

Chomsky, N. (2008). On Phases. In C. Otero et al. (Eds.), Foundational Issues in Linguistic Theory, (pp. 134-166). Cambridge, MA: MIT Press.

Culbertson, J., Smolensky, P., \& Wilson, C. (2013). Cognitive Biases, Linguistic Universals, and Constraint-Based Grammar Learning. Topics in cognitive science 5( 3), 392-424.

Culicover, P. W. (1999). Syntactic nuts: hard cases, syntactic theory, and language acquisition. Oxford: Oxford University Press.

Domínguez, L. (2013). Understanding Interfaces: Second language acquisition and first language attrition of Spanish subject realization and word order variation. Amsterdam: John Benjamins.

Gallego, A. J. (2013). Lexical Items and Feature Bundling: Consequences for Micro-parametric Approaches to Variation. Ms. ICREA-UAB.

Gallego, A. J. (2011). Parameters. In C. Boeckx (Ed.), Oxford Handbook of Linguistic Minimalism. Oxford: Oxford University Press.

Grinstead, J. (2004). Subjects and interface delay in child Spanish and Catalan. Language, 80(1), 4072.

Haegeman, L. (1995). Root Infinitives, Tense, and Truncated Structures in Dutch. Language Acquisition 4, 205-255.

Haider, H. (2012). The VO-OV split of Germanic languages. In H. Haider (Eds.), Symmetry Breaking in Syntax (pp. 97-135). Cambridge University Press.

Hauser, M. D., Chomsky, N., \& Fitch, W. T. (2002). The faculty of language: What is it, who has it, and how did it evolve? Science, 298(5598), 1569-1579.

Holmberg, A., \& I. Roberts. (2009). Introduction: Parameters in minimalist theory. In T. Biberauer, A. Holmberg, I. Roberts, \& M. Sheehan (Eds.), Parametric Variation: Null Subjects in Minimalist Theory (pp. 1-57). Cambridge: Cambridge University Press.

Hyams, N. (2005). Child Non-Finite Clauses and the Mood-Aspect Connection. In P. M. Kempchinsky, M., \& R. Slabakova (Eds.), Aspectual inquiries. (pp. 293-315). Springer.

Kim, M., \& Phillips, C. (1998). Complex verb constructions in child Korean: Overt markers of covert functional structure. In Proceedings of the 22nd Annual Boston University Conference on Language Development (pp. 430-441). Somerville, MA: Cascadilla Press.

Murasugi, K., \& Fuji, C. (2009). Root infinitives in Japanese and the late acquisition of headmovement. BUCLD 33 Proceedings supplement. Available from http://www.bu.edu/bucld/files/2011/05/33-Murasugi.pdf 
Newmeyer, F.J. (2004). Against a parameter-setting approach to language variation. Linguistic Variation Yearbook 4,181-234.

Newmeyer, F.J. (2005). Possible and Probable Languages: A Generative Perspective on Linguistic Typology. Oxford: Oxford University Press.

Orfitelli, R., \& Hyams, N. (2012). Children's Grammar of Null Subjects: Evidence from Comprehension. Linguistic inquiry, 43(4), 563-590.

Paradis, J., \& Navarro, S. (2003). Subject realization and crosslinguistic interference in the bilingual acquisition of Spanish and English: what is the role of the input? Journal of child language, 30(02), 371-393.

Richards, M. (2008). Two kinds of variation in a minimalist system. Linguistische Arbeits Berichte 87, 133-162.

Rizzi, L. (2006). Grammatically-based target-inconsistencies in child language. In eK.U. Deen, J. Nomura, B. Schulz, \& B. D. Schwartz (Eds.), The Proceedings of the Inaugural Conference on Generative Approaches to Language Acquisition|North America, (pp. 19-49). University of Connecticut Occasional Papers in Linguistics, 4.

Roberts, I. \& Holmberg, A. (2005). On the role of parameters in universal grammar: A reply to Newmeyer. In H. Broekhuis et al. (Eds.), Organizing grammar: Linguistic Studies in honor of Henk van Riemsdijk, (pp. 538-553). Berlin: Mouton de Gruyter.

Roberts, I. \& A. Roussou. (2003). Syntactic Change: A Minimalist Approach to Grammaticalization. Cambridge: Cambridge University Press.

Pearl, L. \& Lidz, J. (2013). Parameters in Language Acquisition. In C. Boeckx \& K. Grohmann (Eds.), The Cambridge Handbook of Biolinguistics (pp. 129-159). Cambridge, UK: Cambridge University Press.

Reinhart, T. (2006). Interface strategies. Cambridge, MA: MIT Press.

Salustri, M., \& Hyams, N. (2006). Looking for the universal core of the RI stage. In V. Torrens \& L. Escobar (Eds.), The Acquisition of Syntax in Romance Languages (pp. 159182). Amsterdam: John Benjamins.

Valian, V. (1991). Syntactic subjects in the early speech of American and Italian children. Cognition, 40(1), 21-81.

Varlokosta, S., Vainikka, A., \& Rohrbacher, B. (1998). Functional projections, markedness, and root infinitives in early child Greek. Linguistic review 15, 187-208.

Wexler, K. (1998) Very early parameter setting and the unique checking constraint: A new explanation of the optional infinitive stage. Lingua 106, 23-79.

Yang, C. (2012). Computational models of syntactic acquisition. Wiley Interdisciplinary Reviews: Cognitive Science, 3(2), 205-213.

Yang, C. (2002). Knowledge and learning in natural language. Oxford: Oxford University Press. 


\section{Contact Details:}

Dr. Laura Domínguez

University of Southampton

Modern Languages

Southampton SO17 1BJ

UK

ldo@soton.ac.uk 